\title{
Centestá
}

\section{Demarcações epistemológicas dos estudos de citação: teorias das citações}

\author{
Murilo Artur Araújo da Silveira \\ Doutor; Universidade Federal de Pernambuco, Recife, PE, Brasil; \\ muriloas@gmail.com \\ Sônia Elisa Caregnato \\ Doutora; Universidade Federal do Rio Grande do Sul, Porto Alegre, RS, Brasil; \\ sonia.caregnato@ufrgs.br
}

\begin{abstract}
Resumo: Este artigo revela as demarcações epistemológicas que configuram os estudos de citação na contemporaneidade. Parte-se do pressuposto de que as teorias das citações existentes e amplamente discutidas são antagônicas e complementares. O presente estudo tem como objetivo estabelecer as marcas epistemológicas das teorias normativa e construtivista no âmbito dos estudos de citação. Os elementos que compõem as matrizes epistemológicas das teorias normativa e construtivista são apresentados e discutidos à luz das contribuições presentes na literatura especializada. Conclui-se que as teorias respondem parcialmente os problemas existentes, necessitando buscar aproximações investigativas úteis com outros campos e domínios.
\end{abstract}

Palavras-chave: Estudos de citação. Epistemologia. Teorias das citações. Teoria normativa. Teoria construtivista.

\section{Introdução}

A relação concebida entre os atos de citação e referenciação expressa o vigor e a complexidade dos objetos dos estudos de citação, compreendidos como efeitos resultantes das variadas práticas dos cientistas no domínio da Comunicação Científica. Tais atos percorrem o circuito de apropriação e uso do conhecimento acumulado e disponível, envoltos por elementos objetivos e subjetivos que interligam comunidade e literatura científicas. Como recursos sociais e cognitivos da ciência, citações e referências se integram ao conjunto de práticas científicas que possibilitam expressar a lógica de produção, organização, disseminação, preservação e utilização de informações.

A natureza e as dimensões, a repercussão social e as relações epistemológicas dos estudos de citação reforçam a potencialidade dos elementos de produção, comunicação e utilização do conhecimento que integram o 
conjunto de práticas legitimadas e legitimadoras no/do fazer científico. Ao reconhecer os estudos de citação com tais características, torna-se oportuno evidenciá-los como uma especialidade temática que se consolida por meio da intersecção de saberes teóricos e práticos de diversos campos e domínios, com objetos, objetivos, hipóteses e métodos bem delineados. O reconhecimento da contribuição de específicos campos e domínios, para a constituição dessa especialidade, estabelece o compromisso de aceitação de um conjunto de conhecimentos que se fundem para o entendimento e a resolução de problemas advindos da realidade científica.

Nesse sentido, o realce temático atribuído pressupõe a existência de correntes e enfoques teóricos para a demarcação e alcance dos componentes relacionados. A discussão encontrada na literatura especializada mostra a existência de duas importantes teorias para os estudos de citação: a normativa e a construtivista (LEYDESDORFF, 1998; WOUTERS, 1999; ERIKSON; ERLANDSON, 2014). Tratam-se de postulados teóricos antagônicos orientados para a determinação da matriz epistemológica que envolve os fenômenos e objetos científicos, as metas de pesquisa, os métodos e procedimentos de coleta, organização e análise, os produtos e recursos proporcionados e os resultados, seus alcances e suas limitações (CRONIN, 1998; BALDI, 1998; RIVIERA, 2013).

A literatura especializada explicita os elementos abarcados pelas correntes teóricas dos estudos de citação, mas não há uma sistematização crítica dos limites epistemológicos e dos aportes e recursos envolvidos. Neste espectro de alcance, a questão de pesquisa é: qual a configuração epistemológica das teorias voltadas para os estudos de citação? Assim sendo, admite-se que essas investigações têm elementos, recursos, métodos, produtos e resultados bem definidos, como também a complementaridade e a oposição entre os recortes teóricos frente às proposições colocadas pelos pesquisadores.

No tocante aos pontos evidenciados, esta contribuição tem como objetivo estabelecer as marcas epistemológicas das teorias normativa e construtivista no âmbito dos estudos de citação. Para tanto, enfatiza-se que os tópicos contemplados para a demarcação da matriz epistemológica das teorias normativa 
e construtivista que se pretende nesta contribuição são: objetos, variáveis, objetivos, métodos e técnicas e produtos.

A justificativa para a realização da discussão apresentada é notadamente científica e se destaca como uma tentativa inicial de demarcação epistemológica dos estudos de citação, em busca de qualificação dos alcances e das limitações das correntes teóricas que se voltam às citações e referências. Tal proposição, integrante do conjunto de contribuições sobre os estudos de citação, tenciona discutir criticamente a configuração dos estudos de citação, em uma perspectiva crítica, com o propósito de evidenciar o repertório epistemológico de sua constituição presente na constituição das teorias. Defende-se, assim, a configuração dos estudos de citação como uma especialidade científica dotada de teorias, conceitos e objetos próprios, de métodos, técnicas e instrumentos diversificados, com propósitos e justificativas que regulam suas ações e definem sua identidade. Por se tratar de uma incursão bibliográfica e exploratória, esta revisão, apesar de não ser exaustiva, busca estabelecer as bases epistemológicas dos estudos de citação.

Nesta tônica de distinção entre os enfoques teóricos, as próximas seções se deterão: à trajetória metodológica e delimitação e sistematização dos componentes envolvidos, pautados na análise crítica da revisão bibliográfica disponível.

\section{Trajetória metodológica}

Trata-se de uma pesquisa bibliográfica e exploratória que se concentrou na sistematização de um conjunto de contribuições sobre as concepções teóricas voltadas aos estudos de citação. A incursão bibliográfica foi realizada para levantar as principais correntes teóricas, seus elementos constituintes e as formas de manipulação, organização e análise dos dados e informações que configuram tais estudos. Nesse sentido, apresentam-se as etapas da pesquisa em sua sequência.

a) levantamento bibliográfico - as buscas foram realizadas em duas bases de dados bibliográficas e referenciais : Web of Science (WoS) e Scopus, no período de janeiro a julho de 2016. Para a sistematização das duas 


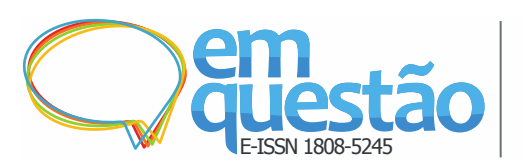

Demarcações epistemológicas dos estudos de citação:

teorias das citações

Murilo Artur Araújo da Silveira, Sônia Elisa Caregnato

correntes teóricas, selecionaram-se textos de cunho teórico e prático que discutiam e problematizavam os tópicos: objeto, variáveis, objetivos, métodos, técnicas e resultados. Registra-se que a seleção dos textos também considerou os seguintes elementos: pertinência teórica construída, posição histórica da publicação e discussão dos resultados alcançados em função da demarcação epistemológica pretendida;

b) sistematização bibliográfica - os textos selecionados foram organizados de acordo com os tópicos escolhidos para definição da matriz epistemológica das teorias das citações. Esta etapa verificou os pontos convergentes entre as contribuições, não somente pelas discussões promovidas por eles, mas também pelas relações estabelecidas pelas citações e referências entre eles;

c) elaboração da matriz epistemológica das teorias - os tópicos elegidos para a composição do esquema de cada teoria foram discriminados após a sistematização bibliográfica, compreendendo os elementos vinculados a cada teoria. A disposição das matrizes será evidenciada nos respectivos capítulos, a seguir.

Ressalta-se ainda que a discussão empreendida nos capítulos, na sequência, foi conduzida por meio dos diálogos estabelecidos com os textos que possibilitaram a composição das matrizes epistemológicas.

\section{Teoria normativa e as formas de produção}

O enfoque normativo pode ser compreendido como o modelo teórico que se orienta pela compreensão do comportamento, da distribuição e da incidência da literatura produzida pela comunidade científica, de forma a permitir generalizações acerca dos elementos objetivos das referências. Os registros bibliográficos arrolados no final dos textos e seus elementos constitutivos são os objetos empíricos de análise por fornecerem os dados e as informações necessárias para a formatação, organização e manipulação destes, pelo princípio de semelhança e diferença. Têm como função a geração de índices absolutos e relativos e suas representações, baseados nas relações entre os itens bibliográficos investigados. Propõem-se também à formulação de metodologias 
alternativas de mensuração e avaliação de objetos empíricos que materializam a produção em ciência e tecnologia, sobretudo àquelas que se concentram na ciência mainstream. Costumam sinalizar como se processam os fluxos de informação entre os pesquisadores, a partir de indicações analíticas e diacrônicas do trajeto científico objetivado de campos e domínios. As formas de apresentação costumam ser por meio de rankings, formatados como tabelas, quadros, gráficos e ilustrações, que expressam modelos de análises, além de muitas relações complexas e multivariadas de proximidade e distanciamento, similaridade, distinção e singularidade, entre outras possibilidades.

A configuração acima explicita o modus operandi dos estudos de citação do enfoque normativo, com objeto, objetivos, métodos e produtos bem delineados, dotados de maturidade e cientificidade que asseguram a constituição de sua matriz epistemológica. Deste postulado é importante destacar que o amparo teórico-metodológico está baseado nos estudos sociais da ciência que privilegiam a medida da atividade científica, regulada por preceitos, prescrições e ditames que asseguram a vitalidade e organicidade dos campos e domínios (LEYDESDORFF, 1998; NICOLAISEN, 2007). O empreendimento de Eugene Garfield, conhecido hoje como Web of Science, viabilizou a realização desses estudos, em meio a um contexto social, científico e técnico que possibilitou a organização desse recurso (GARFIELD, 1974). A lógica que sustenta o instrumento que disponibiliza a produção científica internacional está fundamentada na visão de ciência que se desenvolve livre de interferências externas, permeada por ações genuínas e orientadas pelo compromisso social dos praticantes (LEYDESDORFF; AMSTERDAMSKA, 1990; MERTON, 1977; 2013). Nesse sentido, as métricas de atividade científica se constituem como os indicadores que refletem com exatidão a regularidade cognitiva e social dos campos e domínios.

As referências bibliográficas que figuram ao final dos textos científicos são os objetos preferenciais utilizados dos estudos de citação. A demarcação destes objetos materiais é realizada de forma diacrônica (ocorrências efetuadas ao longo do tempo) e se manifesta por meio dos seus elementos constitutivos (registros referenciados), relacionados (registros que referenciam) e 
sociogeográficos (registros institucionais, espaciais e geográficos de quem referencia). Nesta perspectiva de sistematização, a descrição desses elementos no enfoque normativo é assim estabelecida:

a) elementos constitutivos - autoria (individual e coletiva), título (monografias e de publicações seriadas), tipologia documental, manifestação idiomática, ano de publicação;

b) elementos relacionados - autoria (individual e coletiva), título (monografias e de publicações seriadas), tendência temática, coleção e/ou série documental, ano de produção; e

c) elementos sociogeográficos - vínculo institucional, titulação acadêmica e/ou profissional e região geográfica de atuação.

A operacionalização destes elementos pode ser realizada tanto em sua unidade como em combinação com outros, a depender dos objetivos traçados, das questões formuladas e hipóteses adotadas para comprovação e dos fenômenos a serem compreendidos. Contudo, é necessário frisar que a definição das variáveis é uma parte sensível não somente para a demarcação dos objetos, mas para os objetivos de pesquisa, uma vez que estes componentes estão intimamente vinculados entre si. O destaque para essa tríade se torna oportuna porque a tipificação das possibilidades de variáveis para os estudos de citação permite sinalizar os efeitos que impactam positiva ou negativamente. Para a configuração dos estudos de citação no enfoque normativo, as variáveis costumam se relacionar (TODOROV; GLANZEL, 1988; SMALL, 1999):

a) às indicações de produção e citação - autorias e filiações institucionais;

b) às variações de tempo - demarcação temporal e seus condicionantes (diacronia);

c) às dinâmicas de produção do conhecimento - constituição dos campos e domínios; e

d) às demarcações sociais e geográficas - aspectos espaciais, sociais e contextuais.

$\mathrm{O}$ arsenal instrumental e metodológico dos estudos de citação no enfoque normativo é dotado de sofisticados recursos técnicos e tecnológicos e conduzido por diversificados métodos e técnicas de pesquisa. O conjunto 
significativo de instrumentos voltados à coleta, organização, manipulação e visualização de dados e informações auxiliam e potencializam a realização dos estudos de citação na perspectiva normativa, sobretudo nas duas últimas décadas, conforme apontam Mugnaini, Leite e Leta (2011). A formação desse conglomerado de recursos costuma ser realizada e implementada por governos, agências de fomento, empresas privadas, institutos e centros de pesquisa, universidades, sociedades científicas e profissionais, além de iniciativas pessoais (CRONIN, 1984; COLLINS, 1985; MACROBERTS; MACROBERTS, 1986; WOUTERS et al., 2015), tendo como principais produtos assim sistematizados:

a) instrumentos - softwares e dispositivos digitais de coleta, armazenamento, processamento e representação e outros instrumentos relacionados;

b) repertórios - bases de dados referenciais e bibliográficas, repositórios institucionais e temáticos; e

c) índices - rankings e metodologias de avaliação e produção.

Cabe à técnica análise de citação à exclusividade para a execução de estudos de citação no enfoque normativo. Esta técnica é comumente utilizada com outras técnicas, em especial, as que privilegiam as medidas quantitativas ou que possibilitam gerar indicadores de quantidade da atividade científica, em que torna o enfoque normativo de considerável inclinação quantitativa (CRONIN, 1998; WOUTERS, 1999; MALTRÁS BARBA, 2003). Contudo, observa-se que em algumas investigações a análise de citação é combinada com técnicas de orientação qualitativa, mas também de forma auxiliar em investigações de proposição métrica, em especial as bibliométricas e cientométricas. $\mathrm{Na}$ construção do contorno teórico normativo, a análise de citação se apresenta como a técnica de pesquisa preferencial dos estudos de citação por estabelecer os parâmetros descritivos e analíticos necessários para o estabelecimento da trajetória metodológica e o alcance dos objetivos.

Nas duas últimas décadas, os estudos de citação receberam significativas contribuições da técnica de análise de redes sociais (ARS), sobretudo para a apresentação do comportamento e distribuição das relações entre produção e citação. Por conta da pluralidade teórico-metodológica dessa 
técnica, os estudos de citação se intensificaram em tópicos poucos explorados até então, na medida em que permitiram compreender e visualizar a dinâmica e organicidade da produção de conhecimento sob outros aspectos (ERIKSON; ERLANDSON, 2014). Além disso, o emprego da técnica inseriu outras rotinas para coleta e organização de dados, com o estabelecimento de novos procedimentos de alimentação e manipulação e também introduziu novos instrumentos que alteraram as formas de apresentação e análise de resultados. Paralelamente a estes comentários, registra-se a emergência de novos problemas de pesquisa, a reformatação de antigos, a reformulação de objetivos e hipóteses, que se reconfiguraram em virtude do incremento de acesso aos recursos e instrumentos necessários, em especial ao nível sofisticado dos repertórios bibliográficos e dos softwares.

Os produtos proporcionados pelos estudos de citação, em sua maioria, estão intimamente relacionados com os instrumentos, pois eles são elaborados para se tornarem recursos para outros empreendimentos investigativos, $a$ posteriori. Enquadram-se neste rol de produtos: os repertórios temáticos e institucionais e os índices normalizados de avaliação e produção. No caso dos repertórios bibliográficos, a criação e a posterior utilização desses são contínuas e progressivas, uma vez que as atividades de produção e comunicação da ciência aumentam em volume e avançam no tempo, acarretando atualização e reorganização de dados e registros e uniformização de padrões e formatos (GARFIELD, 1974; SANCHO, 1990; MOED, 2005; WOUTERS et al., 2015). Os índices normalizados são unidades e medidas quantitativas que parametrizam e legitimam os processos de coleta, organização e análise das atividades de pesquisa científica em larga escala e amplitude. Ressalta-se também a forte relação de dependência entre os repertórios e os índices na geração dos produtos do enfoque normativo, pois como destacam Wouters (1999) e Nicolaisen (2007), é desta singular conexão que a dimensão produtiva toma forma e se viabiliza por meio das operações de análise e síntese do considerável volume de documentos. É importante destacar ainda que os produtos gerados desta integração entre os repertórios e os índices são utilizados por agências governamentais, centros e institutos universitários e de pesquisa, entre outros, 
como parâmetros para distribuição e manutenção de recursos financeiros, avaliação e gestão de programas, políticas, instituições, grupos e pesquisadores ligados à atividade científica e tecnológica.

A outra modalidade dos produtos do enfoque normativo se orienta para a apresentação sistêmica e relacional dos processos de manipulação e análise do conjunto de referências e seus elementos, convertidos em indicadores de citação da atividade científica e/ou tecnológica. Diferente da outra modalidade, estes produtos estão baseados em recortes longitudinais da produção científica para análises focadas em objetivos científicos de identificação, avaliação e reconhecimento do comportamento dos campos e domínios, representados pela quantificação das referências bibliográficas e as relações possíveis com os seus e os outros elementos (GLANZEL, 2005). Costumam ser visualizados por indicadores de citação, de relação, de produção, de colaboração, formatados e apresentados em esquemas cartográficos uni e multidimensionais, com vistas à representação pretérita e situacional da produção e uso do conhecimento de campos e domínios da ciência e tecnologia (SANCHO, 1990; SPINAK, 1998; WOUTERS, 1999; MALTRÁS BARBA, 2003; WOUTERS et al., 2015). Têm como metas:

a) mapear e evidenciar influências teóricas e metodológicas que determinam frentes de pesquisa;

b) estabelecer e sinalizar níveis de concentração, dispersão e relação da/entre literatura;

c) recuperar e reconstruir linhagens e trajetórias históricas e epistemológicas; e

d) demarcar e representar as conexões disciplinares entre campos e domínios científicos ao longo do tempo.

Após a apresentação dos elementos que compõem a estrutura do enfoque normativo dos estudos de citação, traz-se à discussão o Quadro 1 que discrimina sinteticamente esta matriz epistemológica. 
Quadro 1 - Matriz Epistemológica do Enfoque Normativo dos Estudos de Citação

\begin{tabular}{|c|c|}
\hline $\begin{array}{c}\text { Enfoque } \\
\text { Normativo }\end{array}$ & Descrição \\
\hline Dimensão & $\checkmark$ Produtiva. \\
\hline Objetos & $\begin{array}{l}\checkmark \text { Referências e seus elementos: } \\
\text { a) constitutivos (registros referenciados); } \\
\text { b) relacionados (registros que referenciam); e } \\
\text { c) sociogeográficos (registros institucionais, espaciais e geográficos de quem } \\
\text { referencia). }\end{array}$ \\
\hline Variáveis & $\begin{array}{l}\checkmark \text { Fatores relacionados: } \\
\text { a) às indicações de produção e citação; } \\
\text { b) às variações de tempo; } \\
\text { c) às dinâmicas de produção do conhecimento; e } \\
\text { d) às demarcações sociais e geográficas. }\end{array}$ \\
\hline Objetivos & $\begin{array}{l}\checkmark \text { Mapear e organizar as referências, seus elementos e suas relações; } \\
\checkmark \text { Elaborar e comparar metodologias e índices quantitativos; e } \\
\checkmark \text { Diagnosticar e analisar os campos e domínios por meio de representações. }\end{array}$ \\
\hline $\begin{array}{l}\text { Métodos e } \\
\text { Técnicas }\end{array}$ & $\begin{array}{l}\text { Método bibliométrico baseado nas técnicas de: } \\
\text { a) análise de citação; e } \\
\text { b) análise de redes sociais. }\end{array}$ \\
\hline Produtos & $\begin{array}{l}\checkmark \text { Construção de instrumentos e procedimentos metodológicos e modelos de } \\
\text { análise e avaliação; } \\
\checkmark \text { Produção de rankings e índices normalizados, absolutos e relativos; e } \\
\checkmark \text { Geração de indicadores e representações gráficas de comportamentos da } \\
\text { produção científica de campos e domínios. }\end{array}$ \\
\hline
\end{tabular}

Fonte: Elaborado pelos autores.

A visão da métrica como indicador qualitativo das práticas científicas objetivadas amplifica os postulados apresentados por Merton, por considerar as reflexões convergentes à noção de ciência pura, governada pelo desinteresse pessoal, desapego material, calcada na recompensa e responsabilidade coletiva para o bem social. Essa dimensão não permite o desenvolvimento da crítica sistematizada dos indicadores provenientes das práticas científicas, aceitando-os como verdade absoluta por expressar ações conectadas com o corpus de conhecimentos consolidados. Ao analisar o enfoque normativo em uma visão ampliada de ciência, percebe-se que as análises das referências bibliográficas se integram à perspectiva sociológica institucional que salienta os imperativos que constituem o ethos da ciência, de um lado, e o sistema de recompensas, do outro, conforme preconizou Merton (MORAVCSIK; MURUGESAN, 1975; SHINN; RAGOUET, 2008; RIVIERA, 2013). A dimensão produtiva que se visualiza no enfoque normativo, em que a medida de ordem quantitativa às referências se sobressai, está voltada de forma mais efetiva para a compreensão da ótica social da institucionalização das ciências, em relação às questões de 
ordem cognitiva. Logo, surge um hiato entre as orientações sociais e cognitivas que permeiam os campos e domínios, com distinção analítica que definem não somente a natureza das investigações realizadas, mas estabelecem as diferenças entre as correntes sociológicas existentes (WHITLEY, 1974; SMALL, 2004; SHINN; RAGOUET, 2008).

O contraponto para tais imperativos é a admissão de que os contextos da ciência influenciam e são influenciados por aspectos e condicionantes políticos, sociais e culturais dentro e fora dos campos e domínios científicos, que afetam as circunstâncias de produção e, por consequência, as medidas oriundas dos elementos que os constitui (FOUREZ, 1995; BOURDIEU, 2004). Para Bourdieu (1983), o campo científico que não admitir a existência de pressões políticas e culturais direcionadas ao seu fazer, não atingiu maturidade suficiente para dimensionar os parâmetros de alcance social de suas ações por falta de compreensão da conjuntura que envolve o convívio em sociedade.

As considerações acerca das influências internas e externas ao campo e a visão mertoniana de práticas científicas genuínas são conflituosas, com marcas sutis de evidência e sustentadas por confrontos que culminam na produção científica (BUFREM, 2014). Dessas operações entre as práticas científicas e os produtos da ciência resulta o que Bourdieu (2011b) instituiu como bens simbólicos, que condiciona não somente a contradição do sistema de ideias e conceitos, mas também a intensificação das ações hierarquizadas entre os envolvidos para os confrontos.

Diante dos pontos apresentados que expressam a dinâmica que circunda o enfoque normativo dos estudos de citação, marcados pelos conflitos entre os segmentos dominantes e dominados, o predomínio da técnica e dos instrumentos e ainda o uso indiscriminado das métricas para representação fidedigna e imparcial da realidade, a produção científica e seus efeitos representam o elemento integrador com os outros elementos do enfoque cognitivo. Com efeito, é importante frisar que o ponto a ser considerado é de que as práticas de citações orientadas para as medidas das referências bibliográficas presentes nas contribuições científicas sinalizam uma das facetas das formulações teóricas para os estudos de citação. Como perspectiva e construção teórica sedimentadas, 
esses estudos determinam e conduzem as diversas formas de produção do fazer científico.

\section{Teoria construtivista e as instâncias de consagração}

O enfoque construtivista dos estudos de citação está interessado em identificar e entender os motivos e as propriedades dos discursos que culminam nos registros objetivos dos pesquisadores em seus textos, na tentativa de revelar os caminhos percorridos para a construção do conhecimento, tanto individual quanto coletivo. Os objetos de análise são as razões das citações dos autores e as conexões estabelecidas com as outras razões, bem como as partes e o todo do texto, partindo do entendimento de que essas relações são dependentes e integradas. Busca levantar e analisar os elementos de persuasão discursiva que determinam os fluxos de produção, comunicação e uso do conhecimento pelos membros das comunidades científicas, com base em critérios de pertinência e relevância que materializem os aspectos subjacentes às menções. Os resultados esperados dos estudos de citação nesse enfoque teórico são generalizações acerca do conjunto de motivos que justificam, historicamente, os hábitos discursivos institucionalizados pelos pesquisadores em um dado campo ou domínio científico. Também são considerados resultados as sistematizações e estruturas classificatórias que balizam o julgamento das razões das citações diante de um quadro de referências.

A configuração do enfoque construtivista está revestida por objetos e objetivos claros e definidos, mas envoltos por elementos subjetivos ligados a fatores psicológicos, políticos históricos, sociológicos e antropológicos que definem a dinâmica das menções (WOUTERS, 1999). O arsenal metodológico pode contemplar métodos e técnicas de forma isolada ou conjunta, instrumentos de coleta e análise de dados de matizes metodológicos de outros campos, definidos assim pela diversidade de possibilidade dos objetivos. As estruturas que parametrizam as razões das citações costumam ser elaboradas: (1) a priori: por meio da sistematização antecipada das respostas ou dos registros das citações dos autores, e (2) a posteriori: por meio da sistematização do conjunto de registros dos autores, ao final, que se acomodam em um quadro sinóptico que 
ilustra os processos de construção do conhecimento (ERIKSON; ERLANDSON, 2014).

Todavia, as pesquisas que partem dessa configuração epistemológica dos estudos de citação devem considerar o princípio arbitrário que acompanha os esquemas classificatórios, redutores da realidade e da lógica que fundamenta o pensamento e a ação humana. Para Ahmed et al. (2004), existem três possibilidades para se estudar as razões das citações, estando elas subordinadas às metas de pesquisas e aos pressupostos lançados pelas investigações. Os autores salientam que as três propostas apresentam vantagens e desvantagens por se direcionarem a questões subjetivas, mas que podem ser combinadas entre si para o alcance de quadros mais representativos.

Os estudos de citação de enfoque construtivista permitem sinalizar não somente como os pesquisadores constroem o conhecimento de forma individual ou coletiva, mas também como se processam a acumulação do conhecimento e suas modalidades, as formas de divulgação e seus propósitos e os níveis de conformação de recursos discursivos entre produtores e consumidores (CASE; HIGGINS, 2000). Na compreensão de que tais possibilidades denotam a riqueza das pesquisas, em virtude da apresentação carregada de subjetividade do objeto, as estruturas categóricas dos esquemas classificatórios são fundamentais porque ajudam a organizar as informações. Aliado a isto, encontram-se discussões sobre a natureza e amplitude de algumas razões de citação que, por mais explícitas que sejam, haverá sempre um aspecto ou viés que não será perceptível ou indicado com exatidão, o seu real objetivo (GILBERT, 1977; LEYDESDORFF, 1998; COMPAGNON, 2007).

Antes do início da discussão sobre os elementos que definem o enfoque teórico construtivista, é importante ressaltar a confusão conceitual entre as funções e as razões das citações à luz dos referenciais teóricos do domínio da Comunicação Científica, o que acarreta equívocos na condução dos trabalhos na perspectiva colocada. A tônica que reveste a imprecisão conceitual entre os termos está relacionada ao comportamento dos pesquisadores, na medida em que os desdobramentos de suas ações constituem o sistema de produção e comunicação da ciência. Configura-se então um conglomerado de ideias e 
práticas amplas, complexas, plurais e dinâmicas, cercado de valores, tradições e regras de conduta científica, sustentado por componentes objetivos e subjetivos (GILBERT, 1977; BORNMANN; DANIEL, 2008). Esses componentes são determinantes para a sustentação do sistema porque definem os parâmetros para as atividades desenvolvidas e seus instrumentos, regulam a prática dos membros das comunidades e estabelecem os marcos teóricos e epistemológicos dos campos científicos (MERTON, 1977; TARGINO; CORREIA; CARVALHO, 2003).

Entende-se por função um papel ou uma ação a desempenhar, uma obrigação a cumprir. Essa atribuição costuma ser realizada por pessoas, grupos, instituições, objetos, recursos, com diversas finalidades e determinadas por um contexto espacial e temporal. Já a noção de razão se determina como uma intenção, um motivo com uma utilidade específica. Tal prática só é realizada por indivíduos ou por um grupo, amparada pelo bom senso e condicionada por fatores psicológicos, sociais e culturais, entre outros. A distinção entre função e razão das citações é estabelecida, assim, por sua finalidade no sistema de comunicação científica e adequadamente explicitada por Garfield (1996) ao apontar as falhas existentes no sistema sobre os mecanismos de citar e referenciar: a função se refere a quando citar, que tem por finalidade a representação de ações, enquanto que a razão a como citar objetiva demonstrar os múltiplos aspectos subjacentes e evidentes da representação das ações. As ponderações do autor se complementam às de Merton (1977) e Ziman (1979) ao afirmar que os princípios que orientam e organizam o sistema, em alguns momentos, são dicotômicos porque envolvem questões voltadas para o cotidiano científico as quais se confrontam com aspectos da vida pessoal e social. No âmbito da Comunicação Científica, a função está voltada para a representação social e a razão para a sustentação dessa representação. Nesses termos, a razão antecede a função, dando sentido à sua realização, como também é mantida e transformada pela função, na medida em que acontecem os avanços teóricos e práticos das regras do sistema de comunicação da ciência.

Tendo em vista a discussão empreendida até agora sobre o enfoque construtivista, que culmina na determinação da precisão de seu objeto científico, 
torna-se necessário enfatizar que esta delimitação deve considerar a relação entre os registros de citação, as características do texto e os contextos de produção. Nessa perspectiva de demarcação, as razões das citações e suas relações objetivas e subjetivas com texto e contexto representam os objetos do postulado teórico construtivista. De forma mais detalhada e baseando-se nas discussões encontradas na literatura (GILBERT, 1977; CHUBIN; MOITRA, 1975), tem-se como objetos do enfoque construtivista:

a) elementos centrais - as razões das citações;

b) elementos textuais - as marcações objetivas que integram as relações entre as razões das citações com os parágrafos, os capítulos e o texto em si; e

c) elementos contextuais - as conexões subjetivas possíveis que se estabelecem entre as razões das citações e os contextos de produção do texto.

É importante frisar que a análise desses elementos não pode ser extrapolada para além do texto e dos contextos de sua produção, uma vez que as razões das citações só adquirem sentido nesta perspectiva teórica por meio da indissociável tríade formada, por conta das múltiplas conexões possíveis que viabilizam novas construções e tessituras textuais. Leydesdorff e Wouters (1999) e Riviera (2013) apontam que a incursão analítica para além desta relação é considerar outros elementos que não correspondem ao propósito do enfoque teórico construtivista, com efeitos que deturpam as apreciações discursivas que podem não estar vinculadas ao fio condutor proposto pela autoria ou associadas a modelos equivocados de apreensão da realidade.

$\mathrm{O}$ conjunto de variáveis que se direciona para as investigações do enfoque construtivista é formado por aspectos persuasivos constitutivos dos textos, formalizados por intenções textuais e influências intelectuais. Trata-se de recursos retóricos para convencimento e refutação de ideias, de motivações para demonstração de conhecimento construído e sedimentado, de interconexões cognitivas e sociais de práticas científicas. As variáveis costumam conjugar aspectos objetivos e subjetivos inerentes à apropriação e produção intelectual com os aspectos históricos, éticos, sociais e culturais envolvidos na 
disseminação e utilização do conhecimento, tendo como resultado reconstruções textuais singulares que expressam o vigor e a dinamicidade da atividade científica (BAVELAS, 1974; SMALL, 1978; LEYDESDORFF, 1987; CASE; HIGGINS, 2000). Dessa forma, as variáveis do enfoque construtivista estão assim dispostas:

a) relacionadas às formas narrativas e retóricas;

b) relacionadas aos gêneros e tipologias textuais;

c) relacionadas às filiações e marcas teóricas e metodológicas; e

d) relacionadas aos contextos de produção e citação.

Para a condução das pesquisas do enfoque construtivista com vistas à visualização da dimensão discursiva que se viabiliza por via da relação entre produção e citação, os recursos metodológicos são diversos e condicionados às variáveis que incidem nas metas estabelecidas. A definição das opções metodológicas deve levar em consideração as possibilidades apontadas por Ahmed et al (2004) para estudos das razões das citações na perspectiva construtivista, haja vista que se propõem três modalidades distintas de observação dos fenômenos que envolvem as práticas científicas. Dessa forma, tem-se a seguinte distribuição metodológica:

a) análise de textos publicados para categorização das razões das citações - técnica de análise de conteúdo, com auxílio de estruturas classificatórias definidas a priori ou a posteriori;

b) entrevista com os autores para identificação dos motivos das citações - técnica de análise de conteúdo, com auxílio de questionários e estruturas classificatórias definidas a priori ou a posteriori; e

c) entrevista com os autores no instante da produção dos textos para destaque dos motivos das citações - técnica de análise de conteúdo, com auxílio de roteiros, esquemas, questionários e estruturas classificatórias definidas a priori ou a posteriori.

A técnica de análise de conteúdo se destaca como a mais utilizada nos estudos de citação de enfoque construtivista, conforme depõem Chubin e Moitra (1975) e Bornmann e Daniel (2008). Tal assertiva sobre a primazia da técnica nos estudos de razões das citações se complementa a de Erikson e Erlandson 
(2014) quando afirmam que sua aplicação encontra as condições favoráveis por se direcionar para textos, depoimentos e respostas com carga semântica e sintática razoável, passível de aglutinação conceitual dos aspectos relacionados às práticas de citação. Além disso, os autores expressam que a referida técnica permite o estabelecimento de categorias e seus níveis hierárquicos e associativos para a construção de esquemas classificatórios e a instrumentalização das formas de análise dos dados e informações.

Outra técnica de pesquisa recorrente nos estudos de citação de enfoque construtivista é a técnica de análise de assunto, frequentemente utilizada de forma complementar à análise de conteúdo, direcionada para a elaboração de classificações (BORNMANN; DANIEL, 2008). O emprego conjunto das técnicas está, na maioria dos casos, voltado para a definição dos termos e suas variações, a associação e hierarquização dos conceitos e a conformação de categorias dos esquemas classificatórios a posteriori. Quando se voltam para os esquemas a priori, as técnicas são acionadas na tentativa de condicionar as respostas e o conteúdo das opiniões, enquanto que para as estruturas $a$ posteriori, o uso das técnicas serve para parametrizar dados e informações obtidas e sistematizar termos, conceitos e categorias.

Cabe registro ainda para os questionários e os roteiros de entrevistas como instrumentos de coleta de dados para o enfoque construtivista. Como ferramentas de obtenção de informação para análises discursivas dos cientistas, são amplamente utilizadas em investigações que objetivam o levantamento dos motivos junto aos pesquisadores, direcionadas para: (1) a determinação das categorias e dos níveis hierárquicos dos esquemas a posteriori; e (2) a orientação e a posterior sistematização das respostas com base na disposição das categorias presentes nos esquemas classificatórios a priori.

Os resultados advindos das pesquisas do enfoque construtivista podem ser observados por generalizações e distinções das variadas e múltiplas motivações que circundam os processos de apropriação e uso do conhecimento que culminam nos atos de disseminação e comunicação científica. A organização do conjunto de razões é resultante da modalidade metodológica que explicita o modus operandi de grupos e segmentos sociais da ciência no que se 
refere às formas de construção do conhecimento que se materializam em registros científicos genuínos, sem desprezos dos fatores e das circunstâncias que incidem nos processos mentais que viabilizam essa construção. Os resultados da dimensão discursiva do enfoque construtivista são visualizados e operacionalizados por esquemas classificatórios construídos antes ou após do/o levantamento das informações junto aos cientistas, respectivamente, de forma a situar, analisar e entender os efeitos persuasivos centrais e adjacentes das menções em contribuições científicas (ERIKSON; ERLANDSON, 2014). Nesse sentido, a disposição dos resultados deste enfoque, conforme aponta a bibliografia especializada (CHUBIN; MOITRA, 1975; GILBERT, 1977; LEYDESDORFF, 1987; CASE; HIGGINS, 2000; ERIKSON; ERLANDSON, 2014), se estrutura em duas possibilidades:

a) generalizações e distinções discursivas - análises sistematizadas das razões das citações e suas conexões com o texto e suas estruturas textuais e semânticas, o contexto da publicação e da especialidade temática; e

b) esquemas classificatórios das motivações - disposição hierárquica, associativa e relacional do conjunto de categorias dos discursos, estabelecidas a priori e a posteriori.

Com base na apresentação dos tópicos que compreendem a estruturação do enfoque construtivista dos estudos de citação, exibe-se o Quadro 2 que discrimina sinteticamente sua matriz epistemológica.

Quadro 2 - Matriz Epistemológica do Enfoque Construtivista dos Estudos de Citação

\begin{tabular}{cl}
$\begin{array}{c}\text { Enfoque } \\
\text { Construtivista }\end{array}$ & \\
\hline Dimensão & $\checkmark$ Discursiva. \\
& $\checkmark$ Razões das citações e suas relações com: \\
& a) os parágrafos; \\
Objetos & b) o texto; \\
& c) o contexto da publicação; e \\
& d) a especialidade temática. \\
& $\checkmark$ Fatores relacionados: \\
& $\checkmark$ às formas narrativas e retóricas; \\
& $\checkmark$ aos gêneros e tipologias textuais; \\
& $\checkmark$ às filiações e marcas teóricas e metodológicas; e \\
& $\checkmark$ aos contextos de produção e citação. \\
& $\checkmark$ Levantar e analisar os motivos de citação dos cientistas, seus recursos \\
&
\end{tabular}




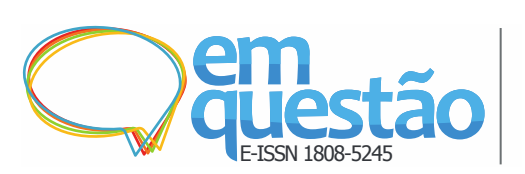

Demarcações epistemológicas dos estudos de citação: teorias das citações

Murilo Artur Araújo da Silveira, Sônia Elisa Caregnato

\begin{tabular}{cll}
\hline & e \\
& $\checkmark$ Elaborar e aplicar estruturas classificatórias dirigidas aos efeitos de \\
& & persuasão dos cientistas e seu entorno social. \\
\hline \multirow{4}{*}{ Métodos e Técnicas } & $\checkmark$ Análise de conteúdo; e \\
& $\checkmark$ Análise de assunto. \\
& $\checkmark$ Elaboração de instrumentos metodológicos voltados para a análise de \\
& & estruturas textuais científicas; e \\
& $\checkmark$ Produção de sínteses gerais e analíticas dos efeitos persuasivos dos \\
& cientistas e dos grupos sociais. \\
\hline
\end{tabular}

Fonte: Elaborado pelos autores.

Ao estabelecer as razões das citações como objeto científico da teoria construtivista por meio de suas relações entre texto e contexto, Gilbert (1977) promove uma aproximação com os postulados de Latour e seu grupo de pesquisa sobre a produção de conhecimento de forma contextualizada. Para tanto, Gilbert (1977) enfatiza que as análises das motivações dos cientistas compreendem uma incursão metodológica baseada na etnografia que se viabiliza pelo binômio texto-contexto, com o propósito de evidenciar como se processam as influências teóricas e metodológicas que se materializam em escolhas bibliográficas passíveis de menções. O autor menciona que os efeitos das escolhas são resultantes das relações causais e tópicos relacionados do contexto para o texto, nessa ordem, em que se conjugam as tradições de pesquisa e as formas de comunicação do conhecimento, aleatória ou sistematicamente. Como consequência, verifica-se um conjunto de práticas de citações que refletem (ou que deveriam refletir) a essência dinâmica da produção e utilização do conhecimento que culmina em produtos textuais registrados e genuínos (GILBERT, 1977).

Para autores como MacRoberts e MacRoberts (1989) e Riviera (2013), a formulação teórica construtivista das citações, embora esteja delimitada por numerosas situações científicas que permitem mapear, visualizar e compreender os fenômenos contemplados, sempre necessitará ser complementada por outras percepções teóricas, incluindo a normativa. De acordo com Zuckerman (1987), MacRoberts e MacRoberts (1989) e Riviera (2013), as críticas mais recorrentes na literatura especializada se direcionam: 


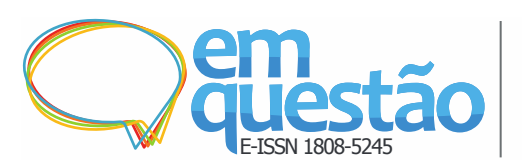

Demarcações epistemológicas dos estudos de citação:

teorias das citações

Murilo Artur Araújo da Silveira, Sônia Elisa Caregnato

a) à complexidade na determinação das motivações dos cientistas (individual e coletivamente) em uma perspectiva sociocognitiva de construção do conhecimento;

b) à multiplicidade de possibilidades metodológicas de visualização das marcas epistemológicas que definem os registros da atividade científica;

c) à pluralidade da integração de dimensões das razões das menções em quadro histórico e epistemológico de disseminação da informação científica consagrada pela comunidade; e

d) ao alcance dos efeitos discursivos e suas intenções e finalidades no escopo das filiações teóricas e metodológicas aceitas pelos integrantes dos campos e domínios.

O conjunto de críticas também é acompanhado de interpretações, sugestões e correções que indicam a dinamicidade desse construto teórico em aplicações que buscam sistematizar categorias discursivas expressas nas citações. Também apontam as deficiências encontradas nas comunicações, em especial às relacionadas ao planejamento e às escolhas metodológicas dos pesquisadores, ao mesmo tempo em que lançam perspectivas para resolução de problemas e conciliação teórico-metodológica. E por fim, enfatizam que a relação entre texto e contexto deve ser repensada, em direção a outras relações que incidem nas formas de produção científica em diferentes campos e domínios. Nesse horizonte de orientação para o enfoque construtivista, os argumentos solicitam interpretações complementares à compreensão construída sobre os contextos e suas influências, não somente revisitando as propostas lançadas por Latour (2000), mas também a convergência com outros postulados que possibilitem e favoreçam os entendimentos estabelecidos.

O foco nas razões dos pesquisadores eleva o discurso científico - e as relações entre as partes e o todo - à condição de instância de consagração por conjugar os outros discursos nas dimensões cognoscitiva, histórica, política, ética e cultural. A distinção destacada pode ser compreendida pela afirmação e oposição dos discursos veiculados nas contribuições do passado, legitimados e aceitos pelos pares por sua singularidade (BUFREM, 2014). Por outro lado, o discurso, em sua proposição dialética entre o existente e o novo, enfatiza duas 
perspectivas que evidenciam os mecanismos de reprodução social: (1) cristalização e perpetuação do conjunto de práticas relacionadas à escrita e, por conseguinte, às razões das citações, que não admitem outras formas de feitura e discussões que incidem sobre o processo de comunicação científica; e (2) inculcação de valores científicos universalmente aceitos e compartilhados por segmentos sociais detentores de capital científico que se materializam nas diversas práticas, como, por exemplo, as citações.

Para Bourdieu (2011a; 2011b), o conceito de capital científico é expresso pelas distintas formas de institucionalização das práticas sociais na ciência, individuais e coletivas. Por seu turno, essas práticas (ou habitus) têm a função de conjugar as experiências do passado com as do presente e do futuro, com vistas à perpetuação dos gostos, dos estilos e das preferências de um segmento social. Contudo, cada integrante desse segmento terá suas próprias experiências, sendo algumas delas compartilhadas e cultivadas com as dos outros, integrando assim o conjunto de habitus do grupo social. Nesse horizonte de agenciamento individual e coletivo dos habitus, em que interesses e ações convergem e divergem em níveis sensíveis de perspectivas, consolida-se o capital científico (BOURDIEU, 2011a; FLEURY, 2009).

Com base nas múltiplas dimensões das razões das citações no contexto científico, sobretudo as relacionadas aos efeitos de distinção e reprodução social, o enfoque construtivista dos estudos de citações assim se determina. Porém, a discriminação desses efeitos consagradores e reprodutores não adquirem, a priori, conotação positiva ou negativa para a realização da pesquisa, partindo do pressuposto que a comunidade é responsável pela dinâmica de preservação e manutenção de valores, crenças e outros aspectos de distinção e reprodução.

\section{Considerações finais}

No processo de delimitação epistemológica dos estudos de citação como especialidade temática, as teorias normativa e construtivista contribuem substancialmente ao propósito por explicitarem os elementos científicos necessários. Em vias antagônicas e complementares, os enfoques teóricos 
discutidos apresentam um repertório amplo de objetos e variáveis diversificados, objetivos e metas bem definidos, métodos, técnicas e resultados diferenciados. Nesse espectro de demarcação epistemológica, visualizam-se aproximações investigativas úteis e possíveis conexões com outros campos e domínios.

As reflexões estabelecidas nesta contribuição foram firmadas e formuladas com base nas interpretações advindas da literatura especializada disponível e acessível que, mesmo não sendo exaustiva, aponta as marcas e bases epistemológicas dos estudos de citação. Contudo, percebe-se que as teorias necessitam de outros elementos e enfoques que ampliem e diversifiquem o arsenal teórico-metodológico que promovam a integração entre elas.

\section{Referências}

AHMED, T. et al. Highly cited old papers and the reasons why they continue to be cited. Part II: the 1953 Watson and Crick article on the structure of DNA.

Scientometrics, Dordrecht, v. 61, n. 2, p.147-156, 2004.

BALDI, S. Normative versus social constructivist processes in the allocation of citations: a network-analytic model. American Sociological Review, Thousand Oaks, v. 63, n. 6, p. 829-846, 1998.

BAVELAS, J. B. The social psychology of citations. Canadian Psychological Review, Calgary, v. 19, n. 2, p. 158-163, 1978.

BORNMANN, L.; DANIEL, H.-D. What do citation counts measure? a review of studies on citing behavior. Journal of Documentation, Bingley, v. 64, n. 1, p. 45-79, 2008.

BOURDIEU, P. A distinção: crítica social do julgamento. São Paulo: EDUSP; Porto Alegre: Zouk, 2011a.

BOURDIEU, P. A economia das trocas simbólicas. São Paulo: Perspectiva, 2011b.

BOURDIEU, P. O campo científico. In: ORTIZ, R. (Org.). Pierre Bourdieu. São Paulo: Ática, 1983. Cap. 4, p.122-155.

BOURDIEU, P. Os usos sociais da ciência: por uma sociologia clínica do campo científico. São Paulo: Ed. UNESP, 2004.

BUFREM, L. S. Faces da produção periódica na Ciência da Informação: o processo de legitimação científica e seus componentes. Informação \& Informação, Londrina, v. 19, n. 3, p. 01-19, 2014. 
CASE, D. O.; HIGGINS, G. M. How can we investigate citation behavior?: a study of reasons for citing literature in communication. Journal of the American Society for Information Science, Maryland, v. 51, n. 7, p. 635-645, 2000 .

CHUBIN, D. E.; MOITRA, S. D. Content analysis of references: adjunct or alternative to citation counting? Social Studies of Science, London, v. 5, p. 443441, 1975.

COLLINS, H. M. The possibilities of science policy. Social Studies of Science, London, v. 15, p. 554-558, 1985.

COMPAGNON, A. O trabalho da citação. Belo Horizonte: Ed. Universitária da UFMG, 2007.

CRONIN, B. The citation process: the role and significance of citations in scientific communication. London: Taylor Graham, 1984.

CRONIN, B. Metatheorizing citation. Scientometrics, Dordrecht, v. 43, n. 1, p. 45-55, 1998.

ERIKSON, M. G.; ERLANDSON, P. A taxonomy of motives to city. Social Studies of Science, London, v. 44, n. 1, p. 1-13, 2014.

FLEURY, L. Sociologia da cultura: e das práticas culturais. São Paulo: Ed. Senac, 2009.

FOUREZ, G. A construção das ciências: introdução à filosofia e à ética das ciências. São Paulo: Ed. UNESP, 1995. (Coleção Biblioteca Básica).

GARFIELD, E. Historiographs, Librarianship and the history of science.

Currents Contents, [S.1.], v. 38, p. 136-150, 1974.

GARFIELD, E. When to cite. Library Quarterly, Chicago, v. 66, n. 4, p. 449458, 1996.

GILBERT, G. N. Referencing as persuasion. Social Studies of Science, London, v. 7, p. 113-122, 1977.

GLANZEL, W. Bibliometrics as a research field: a course on theory and application of bibliometric indicators. [S.1.]: Course Handouts, 2005. Disponível em:

<http://nsdl.niscair.res.in/jspui/bitstream/123456789/968/1/Bib_Module_KUL.p df>. Acesso em: 12 set. 2014.

LATOUR, B. Ciência em ação: como seguir cientistas e engenheiros sociedade afora. São Paulo: UNESP, 2000. 
LEYDESDORFF, L. Theories of citation? Scientometrics, Dordrecht, v. 43, n. 1, p. 5-25, 1998.

LEYDESDORFF, L. Towards a theory of citation? Scientometrics, Dordrecht, v. 12 , n. 5/6, p. 305-309, 1987.

LEYDESDORFF, L.; AMSTERDAMSKA, O. Dimensions of citation analysis. Science, Techonology \& Human Values, Indiana, v. 15, n. 3, p. 305-335, 1990.

LEYDESDORFF, L.; WOUTERS, P. Between texts and contexts: advances in theories of citation?: (a rejoinder). Scientometrics, Dordrecht, v. 44, n. 2, p. 5$25,1999$.

MACROBERTS, M. H.; MACROBERTS, B. R. Problems of citation analysis: a critical review. Journal of the American Society for Information Science, Maryland, v. 40, n.5, p.342-349, 1989.

MACROBERTS, M. H.; MACROBERTS, B. R. Quantitative measures of communication in science: a study of the formal level. Social Studies of Science, London, v. 16, n. 1, p. 151-172, 1986

MALTRÁS BARBA, B. Los indicadores bibliométricos: fundamentos y aplicación al análisis de la Ciência. Gijón: Trea, 2003.

MERTON, R. K. O efeito Mateus na ciência II: a vantagem cumulativa e o simbolismo da propriedade intelectual. In: MARCOVICH, A.; SHINN (Orgs.). Ensaios de sociologia da ciência. São Paulo: Ed. 34, 2013. Cap. 7, p. 199-231.

MERTON, R. K. La sociologia de la ciencia: investigaciones teoricas y empiricas. Madrid: Alianza, 1977. v. 2.

MOED, H. F. Citation analysis in research evaluation. Dordrecht: Springer, 2005.

MORAVCSIK, M. J.; MURUGESAN, P. Some results on the function and quality of citations. Social Studies of Science, London, v. 5, p. 86-92, 1975.

MUGNAINI, R.; LEITE, P.; LETA, J. Fontes de informação para análise da internacionalização da produção científica brasileira. PontodeAcesso, Salvador, v. 5, n. 3, p. 87-102, 2011.

NICOLAISEN, J. Citation analysis. Annual Review of Information Science and Technology, Baltimore County, v. 41, p. 609-641, 2007.

RIVIERA, E. Scientific communities as autopoietic systems: the reproductive function of citations. Journal of the American Society for Information Science and Technology, Hoboken, v. 64, n. 7, p. 1442-1453, 2013. 
SANCHO, R. Indicadores bibliometricos utilizados en la evaluación de la Ciência y la Tecnologia: revision bibliográfica. Revista Española de Documentación Científica, Madrid, v. 13, n. 3-4, p. 842-865, 1990.

SHINN, T.; RAGOUET, P. Controvérsias sobre a ciência: por uma sociologia transversalista da atividade científica. São Paulo: Associação Filosófica Scientia Studia; Ed. 34, 2008.

SMALL, H. Cited documents as concept symbols. Social Studies of Science, London, v. 8, p. 327-340, 1978.

SMALL, H. On the shoulders of Robert Merton: towards a normative theory of citation. Scientometrics, Dordrecht, v. 60, n. 1, p. 71-79, 2004.

SMALL, H. Visualizing science by citation mapping. Journal of the American Society for Information Science, Maryland, v. 50, n. 9, p. 799-813, 1999.

SPINAK, E. Indicadores cienciométricos. Ciência da Informação, Brasília, v. 27, n. 2, p. 141-148, 1998.

TARGINO, M. G.; CORREIA, R. T. P.; CARVALHO, C. P. Quando o amor à ciência ainda basta... In: DUARTE, J.; BARROS, A. T. (Ed.). Comunicação para ciência, ciência para comunicação. Brasília: Embrapa Informação Tecnológica, 2003. p. 19-45.

TODOROV, R.; GLÄNZEL, W. Journal citation measures: a concise review. Journal of Information Science, London, v. 14, n. 1, p. 47-56, 1988.

WHITLEY, R. Cognitive and social institucionalization of scientific specialities and research areas. In: WHITLEY, R. (Ed.). Social processes of scientific development. London: Routledge and Kegan, 1974. p. 69-95.

WOUTERS, P. et al. The metric tide: literature review (supplementary report I to the independent review of the role of metrics in research assessment and management). London: HEFCE, 2015.

WOUTERS, P. The citation culture. 1999. 278f. Tese (Doutorado em Ciências) - University of Amsterdan, Amsterdan, 1999.

ZIMAN, J. Conhecimento público. Belo Horizonte: Itatiaia; São Paulo: EDUSP, 1979. (O Homem e a Ciência, v.8).

ZUCKERMAN, H. Citation analysis and the complex problem of intellectual influence. Scientometrics, Dordrecht, v. 12, n. 5, p. 329-338, 1987. 


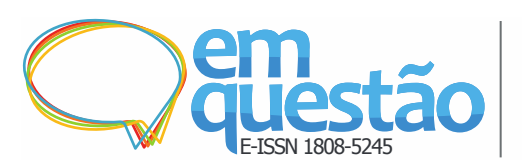

\title{
Epistemological demarcations of citation studies: theories of citation
}

\begin{abstract}
This paper presents the epistemological demarcations that configure the citation studies in the contemporaneity. It is assumed that the theories of the existing citations, widely discussed, are antagonistic and complementary. Its main purpose is to establish the epistemological basis of normative and constructivist theories within the scope of citation studies. It presents and discusses the elements that make up the epistemological matrices of normative and constructivist theories in light of contributions in the specialized literature. It concludes that the theories answer the existing problems partially, necessiting to seek useful investigative approaches with other fields and domains.
\end{abstract}

Keywords: Citation studies. Epistemology. Theories of citation. Normative theory. Constructivist theory.

Recebido: 24/04/2017

Aceito: $18 / 06 / 2017$ 